\title{
INVESTIGACIÓN/RESEARCH
}

\section{NATURALEZA DE LAS NORMAS DEONTOLÓGICAS}

Cristina Fuertes-Planas Aleix: Universidad Complutense de Madrid (España)

\section{Resumen}

La deontología, o ciencia de los deberes de los profesionales, está a caballo entre las normas morales y las normas jurídicas, siendo fundamental que actúan a modo de autorregulación de las personas implicadas. Por ello muchos autores las han calificado como una especie de "tertium genus". Sobre ese aspecto, el acuñamiento del término, en el primer tercio del siglo XIX, sin perjuicio de que su práctica es mucho más antigua, trata este trabajo.

\section{Origen del término "deontología"}

Problema espinoso, aunque de enorme interés. Nos proponemos averiguar si es posible predicar la naturaleza jurídica de las normas deontológicas.

"Deontología" es un término que proviene del griego "deon" (lo obligatorio, lo justo, lo conveniente, lo debido, lo adecuado) y "logos" (tratado, estudio, conocimiento). Aparece tardíamente en el vocabulario jurídico y cuya utilización originaria se debe a Jeremy Bentham (1748-1832), padre del utilitarismo inglés moderno, quien lo utilizó, asumiendo un significado filosófico, en su obra inacabada "Deontología o ciencia de la moralidad", publicada después de su muerte en Londres en 1.834. Le da el significado de estudio o conocimiento de la moral, así como ética de los deberes prácticos, en un sentido diferente al que actualmente tiene. Se configura, por este autor, como una ciencia de los deberes que el hombre debe cumplir para alcanzar la maximización de la felicidad, único fin universalmente realizable.

Battaglia contrapone el significado de las expresiones deontología y ontología, siendo la primera la parte de la filosofía que trata del origen, la naturaleza y el fin del deber; y la segunda, trata de la naturaleza, el origen y el fin del ser.

Lega, por su parte, señala que:

"Aplicada preferentemente a las profesiones intelectuales de antiguo origen histórico, la deontología designa el conjunto de las reglas y principios que rigen determinadas conductas del profesional de carácter no técnico, ejercidas o vinculadas, 'de cualquier manera, al ejercicio de la profesión y a la pertenencia al grupo profesional. Su carácter ético se evidencia en mayor grado en las profesiones coî trasfondo humanitario, como el arte forense y el arte médico."

Recibido: 11/08/1998---Aceptado: 21/10/1998---Publicado: 03/12/1998 http://www.revistaccinformacion.net/publicados.htm 
La profesión, en cuanto constituye un conjunto de hábitos de conducta "en aplicaciones de carácter técnico y dedicación vocacional de las personas, supone un compromiso riguroso con uno mismo y con la sociedad a la que se pertenece." El ejercicio de una profesión supone la realización de una actividad cualificada por los conocimientos y la experiencia, así como por la necesidad de tener los requisitos legales exigidos.

\section{Naturaleza de las normas deontológicas}

Se tiende a considerar las normas deontológicas como reglas de comportamiento que se basan en la costumbre profesional y con un carácter predominantemente moral, aunque no siempre resulta fácil incluir dichas normas entre las meramente morales, y tampoco es posible, en otras ocasiones, clasificarlas dentro de las categorías jurídicas, ya que tienen un claro carácter intrínseco de extrajuridicidad. La deontología de ciertas profesiones se sitúa en un plano intermedio entre el Derecho y la Moral, si bien Santaella señala que la naturaleza de las normas deontológicas es moral, que no constituyen un tertium genus entre el derecho y la ética profesional, sino:

"Un desarrollo de principios morales a partir de la existencia como algo
dado de normas jurídicas; hábitos, usos o costumbres profesionales;
ordenaciones de carácter puramente técnico; situaciones
socioeconómicas del profeséonál y de sus clientes o demandantes de
servicios; regulaciones corporativas de carácter interno, o dirigidas a la
cooperación nacional o internacional entre profesionales u organizaciones
de este carácter, etc."

Su finalidad consiste en el establecimiento de unas normas que garanticen la actuación honesta, tanto en interés de quienes precisan los servicios profesionales, como de la propia colectividad o corporación profesional. Trata de atender a las exigencias de la moral social dominante.

El término deontología, como antes he indicado, significa ciencia de los deberes prácticos, pero no se corresponde, en sentido estricto, con el concepto de moral ordinaria sino (dentro del ámbito general de la ética) con el de las llamadas "morales profesionales", que, por ser morales adquiridas, limitan la libertad del agente con ocasión de actos que realizó él mismo con carácter previo y, en consecuencia, aceptó.

En las morales profesionales se puede obligar la realización de postulados de la moral ordinaria con la finalidad de mantener la existencia de la institución, una vez que ha sido reconocido su valor y los requisitos necesarios para su continuidad.

Que no se trata de una moral ordinaria se constataría, además, por la existencia de un mecanismo sancionatorio institucionalizado. En las morales profesionales se tienen en cuenta los papeles sociales. En caso de conflicto entre la moral profesional y la moral ordinaria prevalecería la primera.

En este punto, parece interesante llamar la atención acerca del paralelismo existente entre los términos moral individual-morales profesionales y deber-obligación. La conveniencia de distinguir entre deber y obligación se puso de relieve por primera vez en H.L.A. Hart. 
La idea clave se encontraría en el hecho de que para que exista una obligación es necesario realizar previa, voluntaria y conscientemente un acto que constituye la condición necesaria de tal obligación, es decir: 1) las obligaciones nacen como consecuencia de la existencia de actos voluntarios, y precisan acciones individuales para su creación. Por ello, tanto en el campo de la moral como en el del derecho, las obligaciones, que en principio hacen que una acción sea moralmente neutra, pierden prima facie su opcionalidad; 2) son interpersonales; 3) cada obligación se correlaciona con su respectivo derecho produciendo, al mismo tiempo, derechos correlativos; 4) se originan en la forma que tienen las partes de vincularse.

El término "deber", en el campo moral podría utilizarse: 1) Con independencia de cualquier acto voluntario que pudiera originarlos (a diferencia de las obligaciones);

2) Como "deberes institucionales", exigencias morales derivadas de la realización de oficios, funciones o papeles sociales que pueden desempeñarse. Se trata de deberes que encuentran una relación mayor con la posición de la persona, que con sus características individuales; 3) Como "deberes de obediencia, que surgen de las leyes que emanan de la autoridad competente.

En definitiva, una obligación presupone la existencia de un acto voluntario y consciente (condición necesaria de la misma).

"Las obligaciones hacen que una acción que era moralmente neutral pierda prima facie su opcionalidad, a la vez que engendran, al mismo tiempo, derechos correlativos. Los deberes, que pueden ser naturales, posicionales o de obediencia, no se adquieren voluntariamente, ni se asumen con abstracción de su contenido. Su función es la de prescribir, enseñar, indicar o aconsejar cuál es la conducta correcta teniendo en cuenta todos los factores relevantes que rodean el caso (deber de juicio final)".

Esta distinción entre deber y obligación tiene relevancia a los efectos que nos proponemos, en la medida en que las obligaciones nacen del consentimiento o de un acuerdo voluntario, pero la obediencia a los deberes no puede fundamentarse exclusivamente en el consentimiento. En ello creo que deriva la dificultad para considerar que las normas deontológicas puedan ser fuente de obligaciones jurídicas sino que, más bien, constituirían deberes (morales y jurídicos).

La juridicidad te las normas deontológicas es un problema de teoría general del derecho, que puede resolverse de diversos modos:

Puede considerarse su carácter no jurídico, sobre la base de que no provienen del Estado, sino de un ordenamiento profesional.

En sentido contrario, puede entenderse la juridicidad del ordenamiento profesional en cuanto es una institución u ordenamiento jurídico particular, o bien, recurriendo a la teoría del hecho normativo. Martínez Val señala que de las fuentes romanas (Tito Livio, Tácito, Cicerón) y de grandes historiadores (Momsem, Barker, Carcopino, Rostowzieff, etc.) surge el convencimiento de que los colegios se producen por:

a) La organización colegial no era derecho en sentido estricto, sino emanación espontánea del orden social;

b) Los colegios tenían capacidad autonormativa para imponerse deberes hacia la sociedad (según puede comprobarse en la obra de Cicerón, "De officis", 3- 
6, 26; y en Séneca, "Epistulae", 95-22). Eran, en gran medida, entidades deontológicas;

c) La igualdad esencial -"democrática, diríamos hoy"- de los colegas, que formaban parte de los colegios, ya que según Ulpiano "en esta denominación se incluyen los que tienen una misma potestad" (Digesto, 50-16-173 y Ad Sap, 38).

Debemos tener presente, en consecuencia, el concepto de institución en cuanto a las cuestiones que vamos a ir replanteando de modo sucesivo.

El ordenamiento profesional es una institución reconocida por el Estado, en cuyas leyes remite al ente profesional la posibilidad de valorar el comportamiento de los profesionales, teniendo la posibilidad de enjuiciarlos, así como de reprimir los que se consideren lesivos a las finalidades del Colegio profesional.

El ente profesional puede, asimismo, declarar los criterios y las normas que informan dichos comportamientos, por lo que no podría negarse el auténtico carácter jurídico de estas normas. Para clasificar las normas deontológicas incluyéndolas en categorías jurídicas, resulta necesario hacer referencia a su origen.

En atención a ello, Carlo Lega sostiene:

a) Si se observa el sistema que acoge el legislador en las leyes profesionales, especialmente las que regulan la profesión forense, resulta fácil que, a través de la remisión a conceptos y parámetros deontológicos, una normativa interna profesional puede consistir, o bien en el reconocimiento de una realidad normativa ya existente (codificación de las tradiciones), o bien en la creación de normas de comportamiento, requeridas para la adecuación de la vida profesional. El ente profesional dicta normas deontológicas, aunque habitualmente se limita a codificar las costumbres, usos y tradiciones existentes con anterioridad, y su labor consiste en verificar su existencia; sólo puntualmente, al hilo de las nuevas necesidades, resulta obligada la creación de nuevas normas, en cuya redacción y aprobación ha de estar presente el espíritu democrático.

El problema de esta normación interna queda resuelto en atención a los principios generales $y$, en consecuencia, al poder que tiene el ente profesional, para su auto-organización y autogobierno, por lo que de él pueden emanar reglamentos internos administrativos de contenido deontológico (su única limitación, en cuanto a su contenido consistiría en el deber de respetar los principios generales del ordenamiento jurídico y las normas primarias del Estado, y su eficacia dependería de la inscripción en el registro).

b) La doctrina tradicional continúa dando primacía, por lo que concierne al aspecto normativo deontológico, a los conceptos de costumbre y de uso normativo, que no agotan toda la materia. No resultaría suficiente tampoco la consideración del carácter supletorio, o bien solamente indicativo de esta normativa, ya que muchas de estas normas contienen órdenes específicas. A juicio de este autor, lo fundamental es la interrelación existente entre el ordenamiento jurídico general y el particular (profesional), que configura un 
cuerpo deontológico relevante jurídicamente, capaz de proyectar su eficacia incluso a los aspectos de la vida privada del profesional, interpretándose también con "reglas de la costumbre (de cortesía, convencionales e incluso de etiqueta y de ceremonial), integrando, de diversas formas, en la ley profesional el tema de los comportamientos no técnicos del profesional.

Precisamente nuestro EGAE, además de regular deberes, que como hemos señalado, son comunes tanôo jurídica como deontológicamente, contiene también importantes alusiones a la normativa deontológica. Así en el art. 42 se dice que el abogado actuará con toda libertad e independencia en el cumplimiento de su misión, sin más limitaciones que las impuestas por la Ley y por las normas de la moral y deontológicas; el art. 48 hage referencia a la obligación de los abogados para con los órganos jurisdiccionales guardando la probidad, lealtad y veracidad en las declaraciones, así como el respeto en las intervenciones; el art. 53 señala las obligaciones del abogado para con su cliente: las que se deriven de la relación contractual, cumplimiento con el máximo celo y diligencia, obligación de guardar el secreto profesional, para lo que debe atenerse "a las exigencias técnicas, deontológicas y morales adecuadas a la tutela jurídica de cada asunto"; el art. 55 hace constar la necesidad de mantener un trato cortés en cada caso con la parte contraria. Ello se debe a la imposibilidad de referirse con detalle a todos los supuestos, por lo que resulta inevitable una remisión a la deontología, garantizada por sanciones disciplinarias que se encuentran previstas y catalogadas en la legislación, pero que son aplicadas por el ente profesional en cada caso concreto de forma discrecional, y de acuerdo con la normativa deontológica.

Esta compleja situación hace difícil la catalogación de las normas susodichas. Se podrían incluir en la muy amplia y elástica categoría de las llamadas reglas sociales o en la igualmente flexible de las normas internas, o, quizá mejor, entre los reglamentos administrativos internos.

Con ello se pondría de relieve la interrelación entre el ordenamiento profesional y el estatal. La vinculación se produce tanto por la remisión del legislador a principios deontológicos, complementarios de la ley (a modo semejante de lo que sucede con los usos normativos), como por la existencia de sanciones, que, aunque impuestas por la institución profesional de modo discrecional, en base a criterios extrajurídicos, adquieren relevancia jurídica por virtud del ordenamiento estatal (suspensión o expulsión del ejercicio de la profesión): normas de naturaleza meta jurídica producen efectos relevantes jurídicamente.

Esta forma de integrar ambos ordenamientos me parece especialmente interesante, ya que existen, en efecto, dos tipos de reglamentos, atendiendo a sus efectos:

- Reglamentos jurídicos normativos, que se refieren a las relaciones de supremacía general. En el ámbito de la doctrina administrativista alemana Otto Mayer- se caracterizan las relaciones de supremacía general como aquéllas que unen al Estado con cualquier ciudadano, afectan a los ciudadanos en cuanto tales (poder de policía o poder tributario: normas abstractas de conducta).

- Reglamentos administrativos de organización, que puede ser, a su vez, -o bien de carácter orgánico, o bien se refieren a los administrados, en(cuanto están incursos en relaciones de supremacía especial (basados en un título 
especial). En las relaciones de supremacía especial los administrados están en una situación de sujeción especial, por lo que la potestad reglamentaria se produce en el ámbito organizativo interno, ámbito doméstico de la organización propia; poder reglamentario no originario, sino derivado. Los reglamentos administrativos son también normas jurídicas, ya que la organización no es ajena al Derecho, sino el mismo origen de lo jurídico (el ordenamiento jurídico es cuerpo social organizado). Aparecen como complementarios de la Ley; por sí mismos no pueden generar obligaciones 0 deberes de supremacía general para los súbditos.

Los Colegios Profesionales son Corporaciones con forma pública de personificación. Salvando todas las diferencias que no vienen al caso en este momento, son Administraciones Públicas en la medida en que son titulares de funciones públicas atribuidas por la Ley o delegadas por actos concretos de la Administración; actúan como verdaderos agentes descentralizados de la Administración. La relación existente entre los inscritos y el Colegio profesional es jerárquica: hay una relación de dependencia a los órganos jerárquicos del mismo, por estar revestidos de su función pública, aunque sean también colegas y exista entre todos ellos una relación de colegialidad.

"Lo propio de estos colegios es defender los ámbitos competenciales de las respectivas profesiones, y aun procurar extenderlos, luchar contra el ejercicio indebido y las competencias desleales de las mismas, perfeccionar las condiciones de ejercicio profesional, promover la cooperación y ayuda entre sus miembros, la protección mutual y la asistencia social de los mismos y de sus familiares, desarrollar su formación y promoción, etc."

Las regulaciones estatal y deontológica se complementan. La regulación simplemente deontológica es aquélla en la que se produce la autorregulación de la propia corporación profesional. El Estado debe intervenir sobre la base de que existen intereses sociales en juego que han de protegerse y, por tanto, controlarse a nivel estatal, pero en las normas estatales han de incluirse contenidos de naturaleza fundamentalmente deontológica.

\section{Bibliografía}

GARZÓN VALDÉS, E,: "Ética y Política”, en Anuario de Filosofía del Derecho, 1984, pág. 177 a 195.

GUASP DELGADO, J.: Derecho Procesal Civil, Madrid 1968.

HART, H. L. A..: “¿Hay derechos naturales?”, en Derecho y Moral. Contribución a su análisis, trad., Genaro Carrió, Depalma, 1962.

LEGA. C. Deontología de la profesión de abogado, Civitas, S.A., segunda edición, Madrid, 1983, pág. 108.

LUNA (DE). A.: Moral profesional del abogado, en AA.VV. "Moral profesional", 
C.S.I.C., Madrid, 1954.

MALEM SEÑA, J. F.: Concepto y justificación de la desobediencia civil, Ariel Derecho, Barcelona, 1990.

MARTÍNEZ VAL, J. Ma: El Abogado: Alma y figura de la Toga, Cabal, Madrid, 1955

Cicerón: el Abogado. En el II Bimilenario de su muerte, en "Foro Manchego" y en "BICAM", 1958.

Ética de la abogacía, segunda edición, Bosch, Barcelona, 1996, pág. 100 a 105.

Abogacía y abogados, Bosch, segunda edición, Barcelona, 1992, pág. 115.

MARTÍ MINGARRO, L.: Abogados, no mercaderes, Revista OTROSí, Colegio de Abogados de Madrid, febrero, 1994.

MONTERO AROCA, J.: Sobre la constitucionalidad de la jura de cuentas (comentario a la Sentencia 110/1993 de 25 de marzo, en "Derecho privado y Constitución, número, 2, 1994.

RAWLS, J.: Teoría de la justicia, Fondo de Cultura Económica, Madrid, 1997.

SANTAELLA, M.: Introducción al derecho de la publicidad, Civitas, Madrid, 1982.

El nuevo derecho de la publicidad, Civitas, Madrid, 1989.

Ética de las profesiones jurídicas. Textos y materiales para el debate deontológico. Servicio de Publicaciones de la Facultad de Derecho de la Universidad Complutense de Madrid y Facultad de Derecho de la Universidad Pontificia de Comillas. Madrid, 1995.

WEBER, M.: Economía y Sociedad, Fondo de Cultura Económica, México, pág. 111 y ss; la primera edición en español es de 1944.

LEGA, C.: Deontología de la profesión de abogado, Civitas, S.A., segunda edición, Madrid, 1983, pág. 23.

LEGA, C.: op. cit., pág. 25 y 26.

SANTAELLA LÓPEZ, M.: Ética de las profesiones jurídicas. Textos y materiales para el debate deontológico. Sdrvicio de Publicaciones de la Facultad de Derecho de la Universidad Com 'lutense de Madrid y Facultad de Derecho de la Universidad Pontificia de Comillas. Madrid, 1995, PÁG. 25.

MALEM SAÑA, J. F.: Concepto y justificación de la desobediencia civil, Ariel Derecho, Barcelona, 1990, pág. 21 y 22.

GARZÓN VALDÉS, E,: "Ética y Política”, en Anuario de Filosofía del Derecho, 1984, pág. 177 a 195. 
MALEM SEÑA, J. V.: op. cit., pág. 22.

H.L.A. HART.: “¿Hay derechos naturales?”, en Derecho y Moral. Contribución a su análisis, trad., GENARO RUBÉN CARRIÓ, Depalma, 1962, pág. 71. Señala exactamente este autor que: a) las obligaciones pueden ser voluntariamente asumidas o creadas; 2) son debidas a personas especiales (quienes son titulares de derechos); 3) no se asignan en el carácter especial de las acciones obligatorias sino en las relaciones entre las partes. Otros autores que han realizado esta distinción, además del propio MALEM SEÑA, J. F.: op. cit., pág. 18 y ss. son JÏHN RAWLS (Teoría de la Justicia, $2^{\underline{a}}$ ed., Trad. M. D. González Solår, Fondo de Cultura Económica, 1997, pág. 306 y ss); RICHARD HARE (EI lenguaje de la moral, trad., GENARO RUBÉN CARRIÓ y EUARDO RABOSSI, UNAM, México, 1975, parte tercera). Asimismo JOEL FEINBERG, HARRY BERAN y REX MARTIN, entre otros, citados por MALEM SEÑA. En España hay autores que se muestran partidarios de tal distinción, como R. ASíS ROIG "Reflexiones sobre el deber y la Obligación", en M. OTERO, M. C. ROVIRA y M. SEGURA (eds.,): "Problemas de la ciencia Jurídica, Estudios en Homenaje al Profesor Francisco Puy", I. Santiago de Compostela, Universidad de Santiago de Compostela, 1991, pág. 21 a 36. También M. J. FALCÓN Y TELLA Concepto y fundamento de la validez del Derecho, Servicio de Publicaciones de la Facultad de Derecho y Civitas, S.A. Madrid, 1994, pág. 43 y ss. Otros autores como R. SORIANO Compendio de Teoría General del Derecho, Ariel Derecho, Barcelona, 1993, pág. 213 sin desconocer la distinción dice: “¿Hay alguna diferencia semántica entre ellos? En principio son términos interdefinibles, y en tal sentido los asumo en mi exposición". Del mismo modo A. MONTORO BALLESTEROS en El deber jurídico $\neg$ Cuadernos de Teoría Fundamental del Derecho, 14. Universidad de Murcia, 1993, pág., 9 dice que en cuanto al establecimiento de los rasgos diferenciadores entre deber jurídico y obligación jurídica, "que no han cristalizado en conclusiones muy convincentes, parece más razonable la posición de quienes (como $\mathrm{H}$. KELSEN, H. NAWIASKY, H. L. A. HART, J. DELGADO PINTO) prefieren utilizar como sinónimos los términos deber jurídico y obligación jurídica." Por lo que respecta a H.L.A. HART, nos remitimos a lo dicho.

Debemos señalar que esta distinción es útil para el estudio de la validez del Derecho, así como la obediencia (o desobediencia) al mismo, pero para el tema que nos ocupa nos parece de suma importancia. Por otra parte, SANTAELLA LÓPEZ, M.: Ética de las profesiones jurídicas. Textos y materiales para el debate deontológico, Servicio de Publicaciones de la Facultad de Derecho de la Universidad Complutense de Madrid y Facultad de Derecho de la Universidad Pontificia de Comillas. Madrid, 1995, pág., 24, señala: "La naturaleza de las prescripciones deontológicas es plenamente moral. La deontología profesional no constituye un "tertium genus", en relación con el derecho y la ética profesional. Constituye más bien un desarrollo de principios morales a partir de la existencia como algo dado de normas jurídicas; hábitos, usos o costumbres profesionales; ordenaciones de carácter puramente técnico; situaciones socio-económicas del profesional y de sus clientes o demandantes de servicios; regulaciones corporativas de carácter interno, o dirigidas a la cooperación nacional o internacional entre profesionales u organizaciones de 
ese carácter, etc. (...) Su incumplimiento puede dar lugar a sanciones efectivas (...) la deontología, aunque desarrolla principios morales y tiene en cuenta, en su caso, la normativa estatal, no se confunde con la ética."

RAWLS, J.: Teoría de la justicia, Fondo de Cultura Económica, Madrid, 1997, pág., 306 y ss. Este autor se refiere a los "deberes naturales" (mutua ayuda, no dañar ni perjudicar a nadie, no causar sufrimientos innecesarios, apoyar y obedecer a las instituciones justas), que no se relacionan con instituciones ni prácticas sociales, ni su contenido viene expresado por reglas que sean producto de ningún acuerdo.

MALEM SEÑA, J. F.: op. cit., pág. 22.

MALEM SEÑA, J. F.: op. cit., pág. 22 y ss. Con el término prima facie (introducido por primera vez por W. DAVID ROSS, en su obra The Right and the Good, 1930) se hace alusión a la idea de que las obligaciones y deberes pueden ser dejados de lado por otros, atendiendo a cada ocasión en particular, a las circunstancias.

MALEM SEÑA, J. F.: op. cit. pág., 21. Este autor cita la obra de JOEL FREINBERG: "Supererogation and Rules", Ethics, n 71, 1961, pág. 277, autor del término "deber de juicio final", señalando que "Mediante el 'deber de juicio final', una vez que se han tomado en consideración todos los factores relevantes que rodean al caso, se indica, prescribe o aconseja a una persona cuál es la conducta que ante esa determinada circunstancia tiene que asumir de manera necesaria e inexcusable."

ROMANO, S.: El ordenamiento jurídico, trad., SEBASTIÁN y LORENZO MARTÍNRETORTILLO, Instituto de Estudios Políticos. Madrld, 1963.

MARTÍNEZ VAL, J. Mª .: Ética de la abogacía, Bosch, S.A., Barcelona, 1996, pág., 228 y ss. Se cuestiona aquí el espinoso problema de la colegiación obligatoria y su repercusión en la libertad de los colegiados. Considera que, aun casi seguros los antecedentes en la Grecia Clásica y en el Oriente mediterráneo, hubo colegios en Roma, antecedentes de los collegia medievales o gremios.

Así se expresa por J. IGLESIAS en su obra Espíritu del Derecho Romano, Universidad Complutense, Madrid, 1980, Cap. II).

MARTÍNEZ VAL, J. Mª̣: Ética de la Abogacía, Bosch, S.A., Barcelona, 1996, pág., 228 y ss. Sería, dice este autor, desde un planteamiento sociológico, una forma de insertarse en la teoría de los cuerpos intermedios de la sociedad. Desde un punto de vista jurídico se ha cuestionado la colegiación obligatoria y la libertad de asociación y de trabajo como conceptos enfrentados. A ello se ha opuesto que se trata de ordenar una profesión que integra la función pública de administrar justicia y no de ejercer ningún tipo de coacción (Sá de Viana); que es necesaria una organización adecuada a su naturaleza y fines (Melitón Romero). La Corte internacional de Derechos Humanos de Estrasburgo el 23 de junio de 1981 ha declarado que la obligación de afiliación a la Orden de 
Médicos en Bélgica no era contraria al art. 11.1 de la Convención Europea de los Derechos Humanos, en cuanto dicha orden no se trata de una asociación, sino de un órgano necesario para el ejercicio de la profesión por su función social. En junio de 1985 la Comisión Interamericana de Derechos Humanos de la OEA ha señalado que "Los Colegios profesionales son instituciones de seguridad social, pues no solamente protegen al profesional, sino también, y de forma especial, a la comunidad social en general al controlar de manera honorable el ejercicio de la profesión".

Si los Colegios profesionales no fueran instituciones reconocidas por el Estado, ¿cómo encajaríamos las obligaciones deontológicas y las respectivas sanciones por incumplimiento desde una perspectiva jurídica? Las fuentes de las obligaciones son los hechos jurídicos de los que nace el vínculo obligatorio. $\mathrm{El}$ art. 1089 indica que las obligaciones nacen de la ley, los contratos, los cuasicontratos y de las acciones y omisiones ilícitas en los que intervenga cualquier género de culpa o negligencia (delito o cuasidelitos civiles; art. 1902 y ss). Las obligaciones pueden serlo: a) Por razones legales (lo mandado está permitido, lo prohibido está castigado; b) Por razones no legales: (permitido: contratos y cuasicontratos, prohibidas (daño): delitos y cuasidelitos. ¿Podría entenderse que la naturaleza jurídica de las obligaciones deontológicas reguladas profesionalmente, ya que no pueden insertarse en el ámbito de la ley, ni en el contrato constituyen un cuasicontrato, no siendo verdaderos contratos por ausencia de una auténtica voluntad o intención contractual, pudiendo existir una serie de figuras heterogéneas? Se trataría de la aplicación analógica y no dialéctica que descubre en un determinado contrato un elemento típico proyectándolo a un determinado acto no contractual. Gayo en las Instituciones (Ins. III, 88) señala que las fuentes de las obligaciones son: el Contrato y el Delito. Los cuasi-contratos generaban obligaciones, tenían ciertas semejanzas con determinados contratos (salvo el acuerdo de voluntades), se les llamó quasi ex contractu (las obligaciones nacían como de contrato), posteriormente se sustantivó: obligaciones que nacen ex quasi contractu obligaciones nacidas de un cuasi-contrato- (Ver: M. ALBALADEJO: Compendio de Derecho Civil, Bosch, Barcelona, 1983, pág. 278). Los cuasi-contratos, caracterizados por la inexistencia de un acto bilateral, cuyos supuestos fueron: negotiorum gestio, legata, communio incidens y solutio indebitio; d) Cuasidelito (actos ilícitos culposos). Las mismas categorías del Derecho romano y del Código de Napoleón (año 1804) que en los artículos 1101 y 1370 agregó la ley fueron recogidas por el Código italiano de 1865, y de éste pasaron a nuestro Código Civil actual. Respondiendo a la pregunta inicial, considero de difícil encaje el cuasicontrato para el tema que nos ocupa. El Código incluye en la categoría de los cuasicontratos la gestión de negocios ajenos (art. 1.888 y ss.) y el cobro de lo indebido (art. 1895 y ss.), ya que la aceptación de la herencia y la comunidad incidental -no establecida por contrato- de bienes de la que nacen obligaciones entre los comuneros; la gestión de la tutela -obligaciones entre pupilo y tutor-; hoy se consideran hechos que procede estudiar en diferentes partes del Derecho. ¿Son posibles en la actualidad otros cuasicontratos? Las STS 8 de enero de 1990 y 21 de junio de 1945 señalan tal posibilidad. M. ALBALADEJO mantiene una opinión contraria (Derecho Civil II vol 2º, Bosch, S.A. Barcelona, 1996, pág. 436): no puede hablarse de 
cuasicontratos atípicos. En los contratos atípicos la obligación nace del acuerdo de voluntades porque el Ordenamiento lo establece en general (art. 1254 y ss); pero en el cuasicontrato el art. 1887 no establece que el cuasicontrato, como figura abstracta, sea fuente de obligaciones (en el fondo los casos resueltos en las sentencias que admiten los cuasicontratos atípicos son 0 de enriquecimiento injusto o de hechos sustancialmente encuadrables dentro de un cuasicontrato típico). En idéntico sentido se pronuncian L. DíEZ-PICAZO y A. GULLON: "Sistema de Derecho Civil", Vol. II., Tecnos. Madrid, 1983, pág. 587. Precisamente para evitar estos problemas, el Código italiano de 1942, en su art. 1173, así como el Código alemán y el suizo, no recogen el cuasicontrato como figura autónoma. Consideran a cada uno de los hechos que nuestro Código denomina cuasi-contratos, como hechos, distintos entre sí, de los que, ex lege, nacen ciertas obligaciones. Las obligaciones nacen de: Contrato, hecho ilícito y de cualquier acto o hecho idóneo para producirlas de conformidad con el ordenamiento jurídico. La Exposición de motivos de la Compilación de Navarra señala que se prescinde de la categoría del cuasicontrato y en su lugar se trata del enriquecimiento sin causa. Los cuasicontratos son casos de él (gestión de negocios, y contrato de mandato como figura similar, pago de lo indebido como caso de enriquecimiento injusto). ALBALADEJO, M.: "Derecho Civil." Tomo I, Bosch, S.A. Barcelona, 1983; parágrafos 14 y 76: Las obligaciones nacen ex voluntate (porque el sujeto quiere, tal como sucede en los negocios jurídicos) o ex lege (porque la ley lo dispone, como sucede con los hechos y actos naturales).

LEGA, C.: op. cit., pág. 57 y ss.

LEGA, C.: op. cit., pág. 57 y ss.

Ver el art. 62 A) $14^{\circ}$ del EGAE respecto a las funciones que corresponden a la Junta de Gobierno de los Colegios profesionales, entre ellas se encuentra la posibilidad de dictar reglamentos internos.

E. GARCÍA DE ENTERRÍA, y T. R. FERNÁNDEZ: Curso de Derecho Administrativo I, Civitas, S.A. Madrid, 1983, pág. 192 a 195. Esta distinción resulta provechosa para examinar la potestad reglamentaria del Consejo de Ministros y la de los simples Ministros que pueden "ejercer la potestad reglamentaria en las materias propias de su Departamento", de acuerdo con el art. 14.3 de la LRJAE. Sólo el Consejo de Ministros puede ejercer la potestad reglamentaria que la Constitución atribuye originariamente a la Administración (normas abstractas de conducta para los ciudadanos. La potestad reglamentaria de los ministros (o autoridades inferiores) es organizativa; salvo habilitaciones legales, el poder reglamentario de los ministros no es originario, sino derivado. El ministro es un jefe administrativo de su Departamento sin supremacía general sobre el pueblo. Este autor y la doctrina alemana han elaborado esta teoría con los términos de "relaciones generales" y "especiales" de poder.

E. GARCÍA DE ENTERRÍA, y T. R. FERNÁNDEZ: op. cit., pág. 378. 
Cristina Fuertes-Planas Aleix 